\title{
Outside the box in Quebec
}

\section{By Michael J. Haas, Senior Writer}

The Quebec Consortium for Drug Discovery has announced C $\$ 1.2$ million in funding for a quartet of projects that are smaller and riskier than those the consortium has been funding since its inception. For all the projects the consortium funds, it expects the results will yield useful research tools for the consortium's pharma members.

Three pharmas-Pfizer Inc., Merck \& Co. Inc. and AstraZeneca plc_founded the Quebec Consortium (CQDM) in 2008. This year, the trio was joined by GlaxoSmithKline plc, Boehringer Ingelheim GmbH and Eli Lilly and Co., and CQDM now includes researchers at 13 academic institutions and hospitals and 11 private companies in Quebec province.

CQDM's primary mission is to develop tools that address industry's drug discovery challenges by funding research at small companies and academic institutions in Quebec, said Diane Gosselin, CQDM's VP of research and business development.

"Industry and academia need to work together at the precompetitive level to develop tools such as drug platforms, biomarkers and diagnostics to help build industry's drug

"Industry and academia need to work together at the precompetitive level to develop tools such as drug platforms, biomarkers and diagnostics to help build industry's drug discovery pipeline." -Patrice Roy, Pfizer Inc. submit proposals and CQDM's advisory board-which includes the pharma sponsors, CQDM's president and CEO Max Fehlmann and Luc Paquet, vice dean of development and partnerships at — decides which project proposals to send for independent peer review by a committee of international experts.

Paquet is also professor and director of Sherbrooke's Institute of Pharmacology.

The committee is coordinated by the Fonds de recherche du Québec-Santé (FRQS), a not-for-profit organization that helps plan and implement healthcare research in Quebec. The committee evaluates the science, while CQDM concurrently evaluates each project for nonscientific risks such as IP, whether the small companies have the necessary infrastructure to fulfill their roles in projects and whether the researchers have sufficient access to samples, patients, equipment and lab space, Gosselin said.

On the basis of those two evaluations, CQDM's advisory board makes recommendations to the consortium's board of directors about which projects should receive funding, she said.

\section{Getting with the program}

CQDM divides programs into two main buckets-called Focus and Explore-depending on the scale of funding required and project goals. Focus funds large-scale, multidisciplinary projects that require $\mathrm{C} \$ 2$ million or more over the course of 3 years and are expected to yield results with immediate applications to participating pharmas' drug discovery efforts, Gosselin said.

She said CQDM has funded 3-4 Focus projects per year, for a total of 11 projects and C\$19.2 million in funding.

An example of a Focus project is a drug delivery platform being developed by researchers at McGill University, the University of Montreal and Polytechnique Montreal. The group's technology uses magnetic resonance to direct bacteria loaded with a liposome-encapsulated drug to tumors.

In another Focus project, researchers at Medicago Inc., Laval University and McGill are developing a high throughput platform based on engineered plants that produce disease antigens for testing as vaccine candidates.

Other researchers from Laval and NDEI Inc. are developing a noninvasive method for stratifying patients with major psychiatric disorders based on retinal responses to photostimulation (electroretinography). According to Gosselin, that team has shown proof of concept for the technique in about 200 schizophrenia patients and is now studying its application in other psychiatric diseases.

In contrast to Focus' broad scale, Explore is intended "to promote true innovation by funding smaller-scale projects that involve unconventional, out-of-the-box thinking," Gosselin said. "These are high-risk projects with the possibility of high rewards if they succeed. Thus, no preliminary data are required-just the potential to produce a 


\section{ANALYSIS}

\section{TRANSLATIONAL NOTES}

breakthrough tool."

Last month, CQDM announced the first funding awards under its Explore program. So far, 4 projects will receive a total of $\mathrm{C} \$ 1.2$ million over the next 2 years. The projects include a computational method being developed at Sherbrooke University for detecting similarities between binding sites of protein targets that could aid drug design and a platform from the National Research Council Canada's Biotechnology Research Institute that uses computational models to design and optimize antibody therapeutics.

CQDM plans to fund three to five projects each in the Focus and Explore programs per year, Gosselin said.

\section{Alsatian rounds}

In addition to Focus and Explore, CQDM has a joint program with Alsace BioValley. CQDM funds research conducted in Quebec, whereas the Alsace cluster funds research conducted in France.

Last month the partners announced they will fund 2 projects at C\$700,000 each.

"We chose Alsace BioValley as a partner based on our shared objectives, our funding levels and our familiarity with the kind of research that was being done in Alsace," said Gosselin. "CQDM's model could be reproduced elsewhere in Canada, the EU or the U.S. because pharmas don't really care where the research is done."

One project-by researchers at the University of Montreal, Domain Therapeutics S.A., the Institute of Genetics and Molecular and Cell Biology, and CRO Mispro Biotech Services Inc.-will develop genetically engineered mice for imaging in vivo interactions between $G$ protein-coupled receptors (GPCRs) and drug compounds.

The other project-by researchers at Laval, Rhenovia Pharma S.A.S. and Photon etc. - will develop platforms that image the effect of drug compounds on neuronal proteins and simulate synaptic signaling mechanisms to predict the effect of drugs on neuronal functions.

In 2010, the partners made their first joint award of $C \$ 700,000$ to researchers at Caprion Proteomics Inc. and the Institute of Cellular and Integrative Neurosciences for a project to identify a marker for neuroendocrine tumors.

\section{Mentor help}

Each Focus and Explore project is assigned one or more senior scientist mentors from CQDM's six pharma sponsors.

"The mentor advises the researchers in Quebec, provides expertise and access to useful resources, and ensures that the project is progressing in line with industry needs," said Gosselin.

Roy added: "The mentor is also someone who can spell out how the results of a project could be used by the companies and thus functions as a liaison between the researchers and the pharmas."

Focus projects have three mentors-one each from AstraZeneca, Merck and Pfizer. Explore projects have at least one mentor from the six pharmas "but could have more, if more than one pharma wanted to have a mentor on the project," Gosselin said. The researchers and pharmas also meet annually in Montreal to review projects.

-Diane Gosselin,

Drug Discovery

She added that the joint projects with Alsace BioValley do not yet have mentors.

Roy said mentoring helps spotlight research activities in Quebec because the mentors come from the pharmas' sites worldwide. "One challenge for us is getting our colleagues at larger research centers in the U.S. and EU to pay attention to research activities at smaller centers," such as those in Quebec and the rest of Canada, he said.

Gosselin said the increased visibility is starting to pay dividends. "While our most advanced projects are only about two years old, the pharmas are already interested in using some of those results," she said.

She added that one pharma sponsor has closed a deal with a research group within the consortium.

Haas, M.J. SciBX 4(41); doi:10.1038/scibx.2011.1135

Published online Oct. 20, 2011

\section{COMPANIES AND INSTITUTIONS MENTIONED}

Alsace BioValley, Illkirch, France

AstraZeneca plc (LSE:AZN; NYSE:AZN), London, U.K.

Biotechnology Research Institute, Montreal, Quebec, Canada

Boehringer Ingelheim GmbH, Ingelheim, Germany

Caprion Proteomics Inc., Montreal, Quebec, Canada

Domain Therapeutics S.A., Illkirch, France

Eli Lilly and Co. (NYSE:LLY), Indianapolis, Ind.

Fonds de recherche du Québec-Santé, Montreal, Quebec, Canada

GlaxoSmithKline plc (LSE:GSK; NYSE:GSK), London, U.K.

Institute of Cellular and Integrative Neurosciences, Strasbourg,

France

Institute of Genetics and Molecular and Cell Biology, Illkirch,

France

Laval University, Quebec City, Quebec, Canada

McGill University, Montreal, Quebec, Canada

Medicago Inc. (TSX:MDG), Quebec City, Quebec, Canada

Merck \& Co. Inc. (NYSE:MRK), Whitehouse Station, N.J.

Mispro Biotech Services Inc., Montreal, Quebec, Canada

National Research Council Canada, Ottawa, Ontario, Canada

NDEI Inc., Sainte-Foy, Quebec, Canada

Pfizer Inc. (NYSE:PFE), New York, N.Y.

Photon etc., Montreal, Quebec, Canada

Polytechnique Montreal, Montreal, Quebec, Canada

Quebec Consortium for Drug Discovery, Montreal, Quebec, Canada

Rhenovia Pharma S.A.S., Mulhouse, France

Sherbrooke University, Sherbrooke, Quebec, Canada

University of Montreal, Montreal, Quebec, Canada 